ARTICLE

Received 9 Nov 2013 | Accepted 28 May 2014 | Published 25 Jun 2014

DOI: $10.1038 /$ ncomms5228

\title{
Made-to-order metal-organic frameworks for trace carbon dioxide removal and air capture
}

Osama Shekhah ${ }^{1,}{ }^{\star}$, Youssef Belmabkhout ${ }^{1}{ }^{\star}$, Zhijie Chen ${ }^{1}$, Vincent Guillerm ${ }^{1}$, Amy Cairns ${ }^{1}$, Karim Adil $^{1} \&$ Mohamed Eddaoudi ${ }^{1}$

Direct air capture is regarded as a plausible alternate approach that, if economically practical, can mitigate the increasing carbon dioxide emissions associated with two of the main carbon polluting sources, namely stationary power plants and transportation. Here we show that metal-organic framework crystal chemistry permits the construction of an isostructural metal-organic framework (SIFSIX-3-Cu) based on pyrazine/copper(II) two-dimensional periodic $4^{4}$ square grids pillared by silicon hexafluoride anions and thus allows further contraction of the pore system to 3.5 versus $3.84 \AA$ for the parent zinc(II) derivative. This enhances the adsorption energetics and subsequently displays carbon dioxide uptake and selectivity at very low partial pressures relevant to air capture and trace carbon dioxide removal. The resultant SIFSIX-3-Cu exhibits uniformly distributed adsorption energetics and offers enhanced carbon dioxide physical adsorption properties, uptake and selectivity in highly diluted gas streams, a performance, to the best of our knowledge, unachievable with other classes of porous materials.

\footnotetext{
${ }^{1}$ Functional Materials Design, Discovery and development (FMD³), Advanced Membranes and Porous Materials (AMPM); Physical Sciences and Engineering Division, King Abdullah University of Science and Technology (KAUST), Thuwal 23955-6900, Kingdom of Saudi Arabia. ${ }^{*}$ These authors contributed equally to this work. Correspondence and requests for materials should be addressed to M.E. (email: mohamed.eddaoudi@kaust.edu.sa).
} 
T he amount of carbon dioxide $\left(\mathrm{CO}_{2}\right)$ in the atmosphere continues to rise and rather rapidly due to unparalleled cumulative $\mathrm{CO}_{2}$ emissions, provoking the undesirable greenhouse gas effect. Certainly, it is becoming critical to develop economical and practical pathways to reduce the $\mathrm{CO}_{2}$ emissions; and appropriately prospective routes to address this enduring challenge are considered: (i) $\mathrm{CO}_{2}$ emission reduction from post-combustion stationary and mobile sources ${ }^{1}$ where $\mathrm{CO}_{2}$ concentration is in the range of $10-15 \%$ and (ii) $\mathrm{CO}_{2}$ removal from air called direct air capture (DAC), which is another alternative option to reduce greenhouse gases emissions in a uniform way globally ${ }^{1-4}$. Although DAC is relatively more challenging than post-combustion capture, it is recognized that it might be practical, provided that suitable adsorbent combining optimum uptake, kinetics, energetics and $\mathrm{CO}_{2}$ selectivity is available at trace $\mathrm{CO}_{2}$ concentration ${ }^{5}$.

In addition, efficient and cost-effective removal of trace $\mathrm{CO}_{2}$ is of prime importance in various key industrial applications pertaining to energy, environment and health. From an industrial perspective, the removal of trace $\mathrm{CO}_{2}$ from air is a growing area of research and development due to its substantial importance for prepurification of air and particularly when atmospheric air is used during the separation of nitrogen and oxygen. In fact, before air separation using cryogenic distillation or pressure swing adsorption, air must be $\mathrm{CO}_{2}$ free to avoid (i) blockage of heatexchange equipment as a result of frozen $\mathrm{CO}_{2}$ during the liquefaction process ${ }^{6,7}$ and (ii) adsorbents (for example, zeolites) contamination used for oxygen production by pressure swing adsorption $^{8-10}$.

Equally important, alkaline fuel cells require a $\mathrm{CO}_{2}$ free feedstock of oxygen and hydrogen gases as it is widely recognized that trace amounts of $\mathrm{CO}_{2}$ (that is, 300 p.p.m.) degrade the electrolyte in alkaline fuel cells ${ }^{11}$. Furthermore, efficient removal of $\mathrm{CO}_{2}$ at low concentrations is also vital for the proper operation of breathing systems in confined spaces such as submarines and aerospace shuttles ${ }^{12-14}$. In fact, in long-term space flight and submarine missions, $\mathrm{CO}_{2}$ must be removed from the air and recycled because resupply opportunities are scarce. An average crew member requires approximately $0.84 \mathrm{~kg}$ of oxygen and emits approximately $1 \mathrm{~kg}$ of $\mathrm{CO}_{2}$ per day ${ }^{14}$. Thus, the ability to continuously purify the exhaled air (with a maximum $\mathrm{CO}_{2}$ concentration of $2-5 \%$ ) will lead to an optimal recycling and considerable reduction in fresh air supply in remote confined spaces.

Efficient $\mathrm{CO}_{2}$ removal and resupply of fresh air is also critical in mining and rescue missions ${ }^{15}$, diving and most importantly in medical applications such as anaesthesia machines ${ }^{16}$. The use of anaesthesia machines is still a growing clinical trend worldwide, driven by the need to reduce cost and improve patient care via the use of efficient $\mathrm{CO}_{2}$ sorbents. The $\mathrm{CO}_{2}$ removal feature in anaesthesia machines is particularly important in semi-closed or closed rebreathing systems, as the rebreathing fraction is at least $50 \%$ of the exhaled gas volume, directed back to the patient after proper $\mathrm{CO}_{2}$ removal in the next exhalation. Sodalime is currently the sorbent of choice in most commercially available anaesthesia machines. This sorbent exhibits a high $\mathrm{CO}_{2}$ removal efficiency from exhaled air, with an average continuous operation of about $24 \mathrm{~h}$ using a prepacked commercial cartridge $^{17}$. Nevertheless, a major drawback of this technology is that one sodalime cartridge can only be used for a single cycle and is nonrecyclable, therefore generating undesirable waste as it should be disposed properly.

Evidently, there is a pressing need to develop novel porous materials ${ }^{18}$ that can adequately address the growing interest in low $\mathrm{CO}_{2}$ concentration removal applications ${ }^{10}$. It is important to mention that only few materials were reported to efficiently adsorb traces of $\mathrm{CO}_{2}$, particularly with regards to DAC using a variety of amine-supported materials (for example, porous silica $^{10,19}$.

Our quest for made-to-order materials that can address efficiently the separation and capture of trace $\mathrm{CO}_{2}$ has prompted us to explore the potential of a burgeoning class of modular and tunable porous materials, namely metal-organic frameworks (MOFs), to tackle this ongoing challenge. Recently, MOFs were investigated intensively for intermediate and high $\mathrm{CO}_{2}$ concentration removal applications such as post-combustion and precombustion capture, natural gas and biogas upgrading ${ }^{20-23}$. Nevertheless, the potential of MOFs to remove trace and low $\mathrm{CO}_{2}$ concentration from gas streams was rarely debated ${ }^{24-28}$. The main reason for this lack of studies is that most of MOFs reported so far, with or without unsaturated metal centres or/and functionalized ligands, exhibit relatively low $\mathrm{CO}_{2}$ uptake and selectivity particularly at relatively low $\mathrm{CO}_{2}$ partial pressure. To overcome this downfall, various research groups have adopted the amine grafting chemistry and the acquired knowledge from amine-supported silica ${ }^{19,22}$ as a prospective pathway to enhance the $\mathrm{CO}_{2}$ adsorption energetics and uptake in MOFs and covalent organic frameworks ${ }^{27-29}$. Particularly, Jones and co-workers ${ }^{28}$ reported for the first time the effect of ethylenediamine grafting on Mg-MOF-74 as a support for $\mathrm{CO}_{2}$ adsorption from ultradilute gas streams such as ambient air. Correspondingly, Long and coworkers investigated the effect of $\mathrm{N}, \mathrm{N}$-dimethylethylenediamine grafting for DAC using an expanded isostructure of Mg-MOF-74 (ref. 27). Markedly, the few reported strategies targeting air capture using MOFs are centred on the aptitude of grafted amines to form a strong chemical bond (at least $70 \mathrm{~kJ} \mathrm{~mol}^{-1}$ ) with $\mathrm{CO}_{2}$, affording high affinity toward $\mathrm{CO}_{2}$ and therefore high $\mathrm{CO}_{2}$ selectivity.

There is no reported study hitherto, to the best of our knowledge, on tuning the pore size of physical adsorption-based MOFs to target trace and low-concentration $\mathrm{CO}_{2}$ removal. In this communication, we report how the reasoned choice of the appropriate MOF platform (here, SIFSIX-3-Cu material), characterized by suitable pore size, combined with the optimal $\mathrm{CO}_{2}$ energetics (that is, strong, uniform and relatively low to allow reversible physical adsorption-desorption), is the key to target made-to-order porous materials for trace and low $\mathrm{CO}_{2}$ concentration removal in general and DAC application in particular.

\section{Results}

Preparation and characterization of SIFSIX-3-Cu analogue. The SIFSIX-3-Cu analogue was successfully prepared by layering a methanol solution of pyrazine in a glass tube onto a methanol solution of $\mathrm{CuSiF}_{6} \times \mathrm{H}_{2} \mathrm{O}$. On layering, an extremely fast formation of light violet powder was observed, which was left for $24 \mathrm{~h}$ in the mother solution. The powder was then collected and washed extensively with methanol then dried under vacuum and characterized using powder X-ray diffraction (PXRD).

The PXRD diagram of SIFSIX-3-Cu analogue studied in this work was found not to match any related reported structures, that is, the $\mathrm{Cu}-2 \mathrm{D}$ structures or the $3 \mathrm{D} \mathrm{Zn}$ analogue reported by Kita and co-workers ${ }^{30}$ (Supplementary Fig. 1). Despite extensive attempts, we were not able to isolate synthetic conditions affording single crystals of sufficient size suitable for single crystal diffraction studies and therefore structural determination by powder diffractometry was explored.

The PXRD pattern of the crystalline powder, resulting from the reaction of $\mathrm{CuSiF}_{6} \times \mathrm{H}_{2} \mathrm{O}$ with pyrazine in methanolic solution, was recorded on a high resolution PANalytical X'Pert MPD-PRO diffractometer with $\mathrm{Cu}-\mathrm{K} \alpha$ radiation $(\lambda=1.5406 \AA)$ in the range 
of 4 to $80^{\circ}$ using a step of $0.05^{\circ}$ ( $250 \mathrm{~s}$ per step). The indexation of the PXRD diagram, carried out using the McMaille software ${ }^{30}$, yielded a primitive orthorhombic cell $(M(20)=42.3$ and $F(20)=39.9(0.0139,36))$. The cell parameters, $a=b=$ 6.919(1) $\AA, c=7.906(1) \AA$, were refined by a whole powder pattern fit using the Le Bail method ${ }^{31}$, implemented in the FULLPROF software ${ }^{32}$, and were consistent with those of the previously described SIFSIX-3-Zn. Hence, atomic positions of the latter were used as structure solution. The final Rietveld refinement permitted access to satisfactory results: $R_{\mathrm{Bragg}}=0.051$ and $R_{\text {Factor }}=0.056$ (Supplementary Fig. 2). The crystallographic data and refinement parameters of SIFSIX-3-Cu are summarized in Supplementary Table 1.

As initially expected, it is in very good agreement with the $3 \mathrm{D}$ structure of the Zn analogue reported previously (Fig. 1), but with a slightly smaller unit cell $\left(378\right.$ versus $\left.388 \AA^{3}\right)$ attributed to the relatively stronger bonding between the $\mathrm{Cu}(\mathrm{II})$ and the pyrazine (Supplementary Data 1, Supplementary Table 2). The smaller unit cell of the $\mathrm{Cu}$ analogue is in good agreement with the relatively sharp pore size distribution analysis centred at $3.5 \AA$ (average pore size), as determined from the $\mathrm{CO}_{2}$ adsorption isotherms, using NLDFT model, which shows a smaller average pore size than the SIFSIX-3-Zn (3.5-4 $\AA$ ) (Fig. 2a). The thermal gravimetric analysis of the SIFSIX-3-Cu showed a weight loss of about $10 \%$ for the dried sample in the range of $50-150^{\circ} \mathrm{C}$ attributed to guest molecules (Supplementary Fig. 3). Further gradual loss was observed above $150^{\circ} \mathrm{C}$ and attributed to the framework

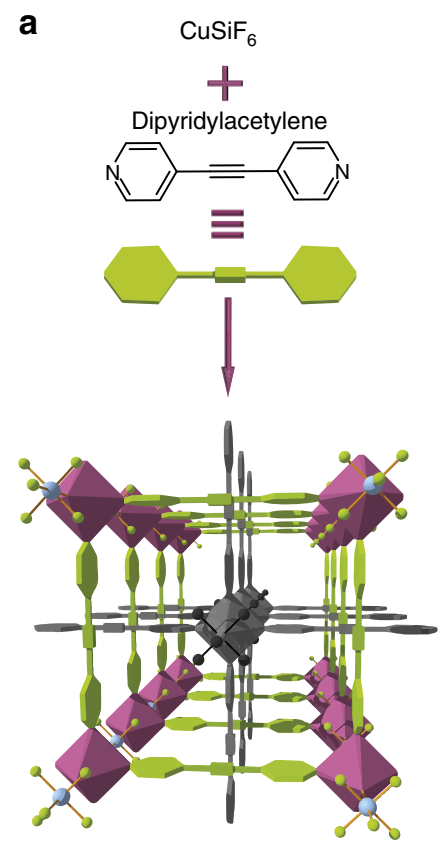

SIFSIX-2-Cu-i
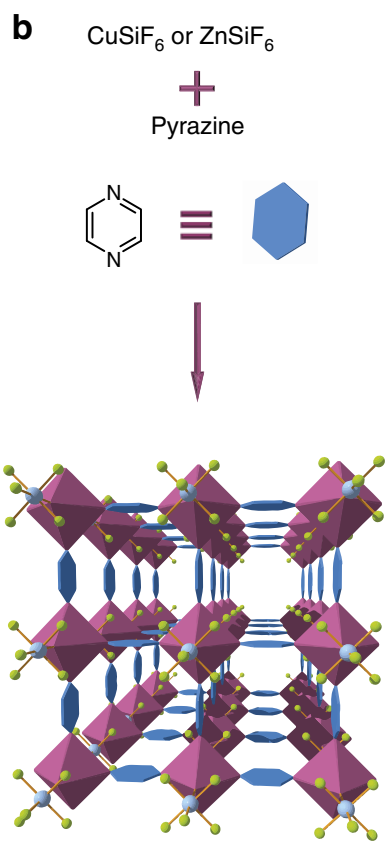

SIFSIX-3-Cu/Zn
Figure 1 | Pore size tuning. Pore size tuning of the channel structures of (a) SIFSIX-2-Cu-i, (b) SIFSIX-3-Zn or/and SIFSIX-3-Cu. (a) SIFSIX-2-Cu-i; pores size $5.15 \AA$, Brunauer-Emmett-Teller (BET) apparent surface area ( $\mathrm{N}_{2}$ adsorption) $735 \mathrm{~m}^{2} \mathrm{~g}^{-1}$. (b) SIFSIX-3-Zn; pores size $3.84 \AA$, BET apparent surface area $250 \mathrm{~m}^{2} \mathrm{~g}^{-1}$ (determined from the $\mathrm{CO}_{2}$ adsorption isotherm at $298 \mathrm{~K}$ ); SIFSIX-3-Cu; pores size $3.50 \AA$ (NLDFT), BET and langmuir apparent surface area ca. $300 \mathrm{~m}^{2} \mathrm{~g}^{-1}$ (determined from the $\mathrm{CO}_{2}$ adsorption isotherm at $298 \mathrm{~K}$ ). Colour code: Dipyridylacetylene (dpa, thick light green polygon), pyrazine (pyz, blue polygon), Zn, Cu (purple polyhedra), Si (light blue spheres), F (light green spheres). All guest molecules are omitted for clarity. Note that the grey net represents the interpenetrated net in SIFSIX-2-Cu-i. decomposition. The thermal gravimetric analysis data for the SIFSIX-3-Cu is in a good agreement with the one reported for the SIFSIX-3-Zn analogue. Infrared spectrum for the SIFSIX-3-Cu (Supplementary Fig. 4) exhibits bands characteristic of the $\mathrm{C}-\mathrm{H}$ aromatic bonds associated to the pyrazine moiety at 3,114 and $3,073 \mathrm{~cm}^{-1}$ and bands characteristic for the $\mathrm{C}-\mathrm{N}$ bond at 1,445 , 1,122 and $1,070 \mathrm{~cm}^{-1}$. Furthermore, the characteristic bands associated with the octahedral $\mathrm{SiF}_{6}$ were also observed at 743 and $833 \mathrm{~cm}^{-1}$ (ref. 33).

$\mathrm{CO}_{2}$ adsorption studies. In order to evaluate the potential of SIFSIX-3-Cu for $\mathrm{CO}_{2}$ capture, we performed various $\mathrm{CO}_{2}$ adsorption studies. It was our preconception that this new $\mathrm{Cu}$ analogue should at least show the same promising adsorption properties as the SIFSIX-3- $\mathrm{Zn}^{23}$. The $\mathrm{Cu}$ analogue shows even steeper variable temperature adsorption isotherms (Fig. 2a) at very low pressure indicative of relatively stronger $\mathrm{CO}_{2}$ - SIFSIX-3$\mathrm{Cu}$ interactions than the $\mathrm{Zn}$ analogue

In order to further explore the possible sorption mechanistic behind this relatively enhanced uptake at low $\mathrm{CO}_{2}$ loading, we explored the competitive adsorption kinetics of $\mathrm{CO}_{2} / \mathrm{N}_{2}: 10 / 90$, $\mathrm{CO}_{2} / \mathrm{CH}_{4}: 50 / 50, \quad \mathrm{CO}_{2} / \mathrm{H}_{2}: 30 / 70$ gas mixture adsorption (Supplementary Fig. 5). As anticipated and based on similar studies carried out on the $\mathrm{Zn}$ analogue ${ }^{23}$, the uptake at equal times, including at equilibrium, for variable $\mathrm{CO}_{2}$ compositions mixtures follows the behaviour of pure $\mathrm{CO}_{2}$. These findings suggest that similarly to the mechanistic suggested for SIFSIX-3$\mathrm{Zn}$, when $\mathrm{CO}_{2}$ containing mixtures are in contact with SIFSIX-3$\mathrm{Cu}, \mathrm{CO}_{2}$ adsorbs more strongly (Supplementary Fig. 6) and rapidly than $\mathrm{N}_{2}$ and by analogy also $\mathrm{O}_{2}, \mathrm{CH}_{4}$ and $\mathrm{H}_{2}$ (Supplementary Fig. 5), thus occupying favourably most of the

a
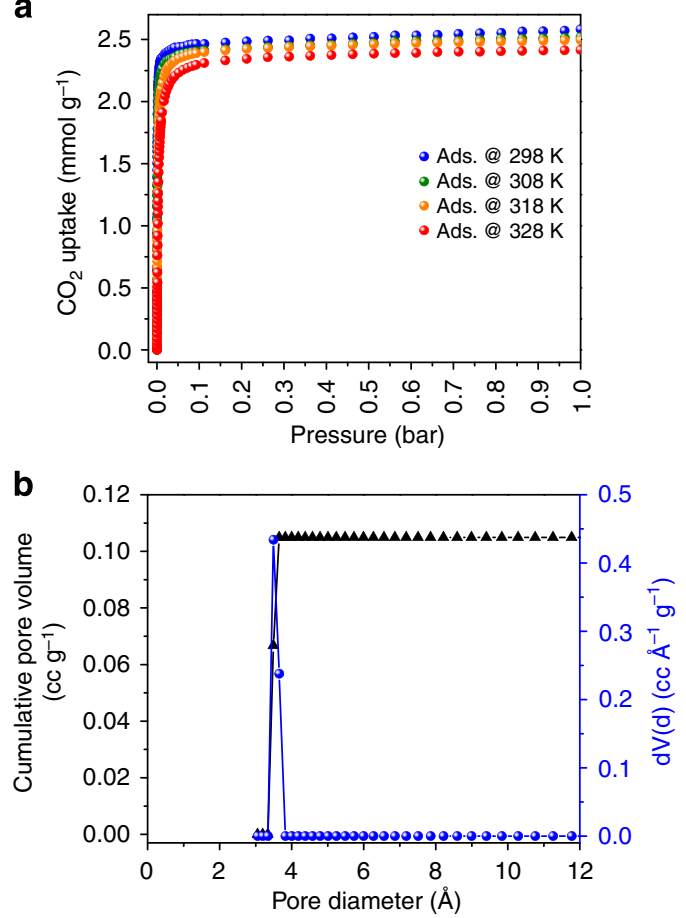

Figure $\mathbf{2}$ | $\mathbf{C O}_{\mathbf{2}}$ adsorption isotherms. $\mathrm{CO}_{2}$ adsorption isotherms at variable temperatures for SIFSIX-3-Cu. The SIFSIX-3-Cu analogue shows asteeper variable temperature adsorption isotherms at very low pressure indicative of strong $\mathrm{CO}_{2}$-SIFSIX-3-Cu interactions. (a) pore size distribution (PSD) derived from the $\mathrm{CO}_{2}$ sorption isotherm $\left(\mathrm{CO}_{2}\right.$ at $273 \mathrm{~K}$ NLDFT) for SIFSIX-3-Cu. The PSD extracted from adsorption isotherms, shows an average pore size for SIFSIX-3-Cu centred at $3.5 \AA(\mathbf{b})$. 
available space and adsorption sites and subsequently exclude other gases, a desirable feature in many $\mathrm{CO}_{2}$ separation and purification applications.

Interestingly, on the substitution of $\mathrm{Zn}$ by $\mathrm{Cu}$, the $\mathrm{Q}_{s t}$ of $\mathrm{CO}_{2}$ adsorption in the contracted structure increased by $20 \%$, from 45 to $54 \mathrm{~kJ} \mathrm{~mol}^{-1}$ (Fig. 3b), in perfect agreement with the relatively steeper $\mathrm{CO}_{2}$ adsorption isotherms in the case of the $\mathrm{Cu}$ analogue at very low pressure.

Column breakthrough experiments. Furthermore, the $\mathrm{CO}_{2}$ selectivity for SIFSIX-3-Zn and SIFSIX-3-Cu was investigated experimentally at trace $\mathrm{CO}_{2}$ using column breakthrough tests for binary $\mathrm{CO}_{2} / \mathrm{N}_{2}$ : 1,000 p.p.m./99.9\% mixture (Fig. $4 \mathrm{a}$ ) at $298 \mathrm{~K}$ in dry as well as in humid conditions. The derived selectivity at breakthrough time (and not equilibrium) is intended to reflect the real selectivity in real processes. In a dry condition, the first $\mathrm{CO}_{2}$ signal downstream the column was observed only after ca. 798 and ca. 1,922 $\mathrm{ming}^{-1}$ for SIFSIX-3-Zn and SIFSIX-3-Cu, respectively, after starting continuous $\mathrm{CO}_{2} / \mathrm{N}_{2}$ gas mixture flux $\left(5 \mathrm{~cm}^{3} \mathrm{~min}^{-1}\right)$, while $\mathrm{N}_{2}$ breakthrough occurred immediately in few seconds. Accordingly, at 1,000 p.p.m. $\mathrm{CO}_{2}$ and breakthrough time, SIFSIX-3-Cu shows higher selectivity (ca. 10500) than
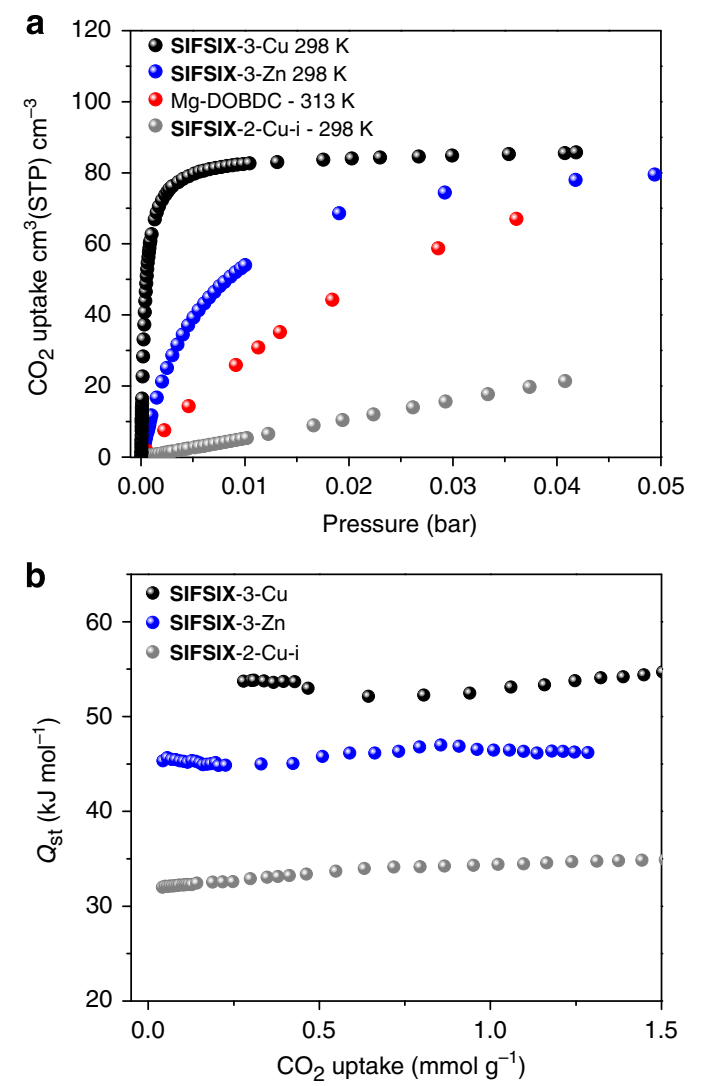

Figure 3 | $\mathbf{C O}_{2}$ volumetric uptake. $\mathrm{CO}_{2}$ volumetric uptake for SIFSIX-3- $\mathrm{Cu}$ at $298 \mathrm{~K}$ compared with SIFSIX-3-Zn, SIFSIX-2-Cu-I and Mg-MOF-74. The adsorption results at very low pressure (400 p.p.m.-5\%) for the SIFSIX-3$\mathrm{Cu}$ showed that the $\mathrm{Cu}$ analogue exhibits steeper adsorption isotherms at very low $\mathrm{CO}_{2}$ concentration in comparison with other materials. At 7.6 torr (0.01 bar), SIFSIX-3-Cu uptakes $82.6 \mathrm{~cm}^{3}(\mathrm{STP}) / \mathrm{cm}^{-3}$ versus 55 and $28 \mathrm{~cm}^{3}(\mathrm{STP}) / \mathrm{cm}^{-3}$ for SIFSIX-3-Zn and Mg-MOF-74, respectively (a). Isosteric heats of adsorption at low coverage for SIFSIX-3-Cu, SIFSIX-3-Zn and SIFSIX-2-Cu-I. The $Q_{s t}$ for SIFSIX-3-Cu was observed to be higher than the $\mathrm{Zn}$ analogue and steady constant up to relatively higher recorded $\mathrm{CO}_{2}$ loadings. This is indicative of the presence of homogenous binding sites over the full range of $\mathrm{CO}_{2}$ loading for SIFSIX-3-Cu (b).
SIFSIX-3-Zn (7259). It is to mention that calculated and measured selectivity exceeding 1,000-2,000 are often subject to uncertainties associated with measurement of the gas uptake of weakly adsorbed gases $\left(\mathrm{N}_{2}\right.$; Supplementary Fig. 6) in the mixture, thus the reported selectivity is aimed mainly for relative comparison of the studied compounds in this work. In view of that, a direct comparison between the SIFSIX-3-Cu and the SIFSIX-3-Zn sorption properties show a $50 \%$ relative increase in $\mathrm{CO}_{2}$ selectivity at $1,000 \mathrm{ppm} \mathrm{CO}_{2}$ in a $\mathrm{N}_{2}$ stream (ca. 10500 versus 7259). The steeper $\mathrm{CO}_{2}$ signal after breakthrough for SIFSIX-3- $\mathrm{Cu}$ as compared with the $\mathrm{Zn}$ analogue is a direct indication of the steeper $\mathrm{CO}_{2}$ adsorption for the $\mathrm{Cu}$ analogue as shown in Fig. 3a.

\section{Discussion}

Recently, we reported $\mathrm{CO}_{2}$ adsorption study on a series of isoreticular MOFs with periodically arrayed hexafluorosilicate (SIFSIX) pillars, called SIFSIX-2-Cu-i and SIFSIX-3-Zn (Fig. 1 $)^{23}$. The aforementioned porous MOFs having a combination of tunable pore size (rather than large surface area) coupled with the requisite chemistry led to materials with uniformly aligned strong $\mathrm{CO}_{2}$ adsorption sites and subsequently
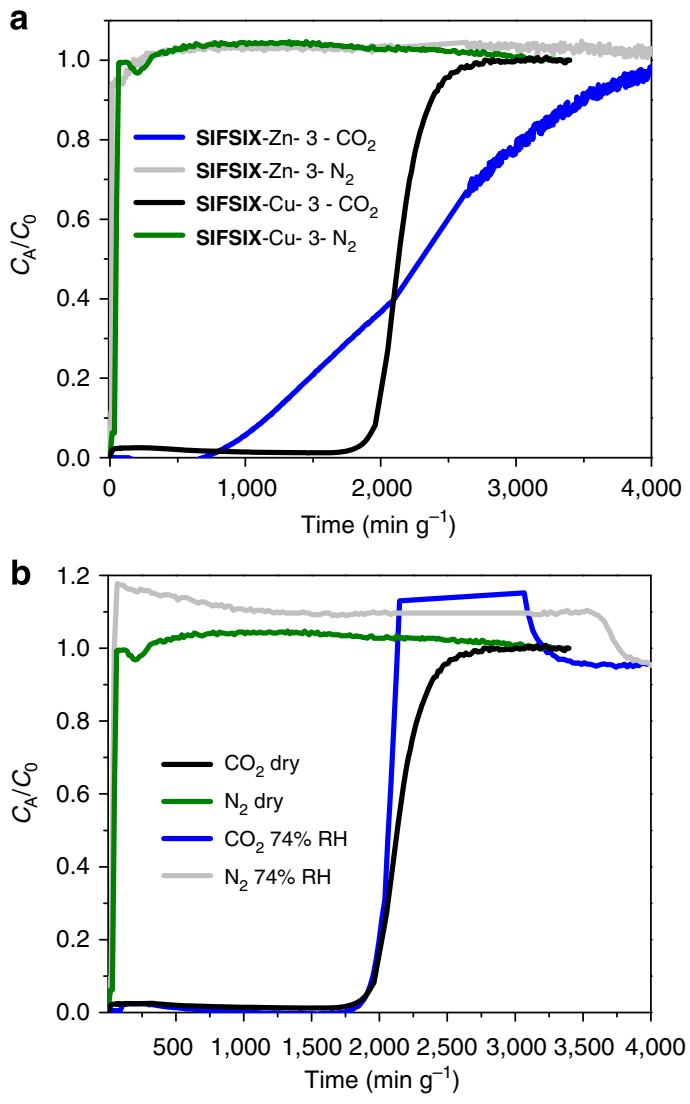

Figure 4 | Column breakthrough experiments. Column breakthrough test of $\mathrm{CO}_{2} / \mathrm{N}_{2}: 1,000$ p.p.m./99.9\% for SIFSIX-3-Cu, SIFSIX-3-Zn in dry condition (a). Column breakthrough test of $\mathrm{CO}_{2} / \mathrm{N}_{2}: 1,000$ p.p.m./99.9\% for SIFSIX-3-Cu in dry as well as at $74 \% \mathrm{RH}(\mathbf{b})$. The $\mathrm{CO}_{2}$ selectivity for SIFSIX-3-Zn and SIFSIX-3-Cu was investigated experimentally at trace $\mathrm{CO}_{2}$ using column breakthrough tests for binary $\mathrm{CO}_{2} / \mathrm{N}_{2}: 1,000$ p.p.m./99.9\% mixture at $298 \mathrm{~K}$ in dry as well as in humid conditions. In dry condition, the first $\mathrm{CO}_{2}$ signal downstream the column was observed only after ca. 798 and ca. $1922 \mathrm{~min}^{-1}$ for SIFSIX-3-Zn and SIFSIX-3-Cu, respectively, after starting continuous $\mathrm{CO}_{2} / \mathrm{N}_{2}$ gas mixture flux $\left(5 \mathrm{~cm}^{3} \mathrm{~min}^{-1}\right)$, while $\mathrm{N}_{2}$ breakthrough occurred immediately in few seconds. 
exhibiting a relatively fast and highly selective $\mathrm{CO}_{2}$ behaviour over $\mathrm{N}_{2}, \mathrm{CH}_{4}$ and $\mathrm{H}_{2}$ (ref. 23). Particularly, the denser isoreticular analogue, namely SIFSIX-3-Zn, revealed steeper variable $\mathrm{CO}_{2}$ adsorption isotherms (Supplementary Fig. 7) than SIFSIX-2-Cu-i (Supplementary Fig. 8). This material exhibits unique key features suitable for post-combustion capture (that is, the $\mathrm{CO}_{2}$ partial pressure of $100 \mathrm{mbar}$ ), as well as precombustion capture (that is, high $\mathrm{CO}_{2}$ concentration and high pressure).

The pronounced steep $\mathrm{CO}_{2}$ adsorption isotherms over a wide range of temperatures, particularly for this class of MOF materials, has inspired and compelled us to explore the potential of these SIFSIX MOFs for $\mathrm{CO}_{2}$ adsorption in trace concentrations (that is, diluted streams in vacuum or in mixture containing a large fraction of $\mathrm{N}_{2}$ up to $95 \%$ ). In order to highlight the concealed potential of these MOFs for low $\mathrm{CO}_{2}$ concentration applications (that is, involving $\mathrm{CO}_{2}$ concentration below $5 \%$ or $50 \mathrm{mbar} \mathrm{CO}_{2}$ partial pressure, such as anaesthesia machines and prepurification before air separation and air capture), single gas $\mathrm{CO}_{2}$ adsorption properties were evaluated for SIFSIX-2-Cu-i and SIFSIX-3-Zn. Interestingly, the contraction of the pore size from $5.15 \AA$ (for SIFSIX-2-Cu-i) to $3.84 \AA$ (for SIFSIX-3-Zn) has prompted a drastic increase in $\mathrm{CO}_{2}$ uptake (Supplementary Fig. 9 ) and consequently a recorded highest $\mathrm{CO}_{2}$ uptake ever reported for a given $\mathrm{MOF}$ in the range under $5 \% \mathrm{CO}_{2}$. Specifically, SIFSIX-3-Zn showed an order of magnitude higher volumetric $\mathrm{CO}_{2}$ uptake $\left(55 \mathrm{~cm}^{3}(\mathrm{STP}) / \mathrm{cm}^{3}\right)$ than to date best MOF materials such as Mg-MOF-74, $\left(28 \mathrm{~cm}^{3}(\mathrm{STP}) / \mathrm{cm}^{3}\right)$ at $10 \mathrm{mbar}\left(1 \% \mathrm{CO}_{2}\right)$, while UTSA-16 (ref. 34), exhibits much lower $\mathrm{CO}_{2}$ uptake similar to SIFSIX-2-Cu-i.

The noticeable impact of pore size contraction on the adsorption energetics and uptake has impelled us to explore various pathways to further reduce the pore size of the SIFSIX-3$M$ derivative via metal substitution and evaluate its effect on the $\mathrm{CO}_{2}$ adsorption properties. The rational is based on conventional coordination chemistry suggesting that replacement of $\mathrm{Zn}$ (II) by $\mathrm{Cu}$ (II) to form an isostructural SIFSIX-3-Cu will potentially induce an additional pore contraction due to Jahn-Teller distortions of the octahedral coordination geometry of $\mathrm{Cu}(\mathrm{II})$, $\mathrm{CuN}_{4} \mathrm{~F}_{2}$. The $\mathrm{Cu}(\mathrm{II})$ has an open shell valence electron configuration $3 \mathrm{~d}^{9}$, in contrast to $\mathrm{Zn}(\mathrm{II})$ with a close shell $3 \mathrm{~d}^{10}$, and thus will experience a distorted octahedral coordination geometry with potentially elongated $\mathrm{Cu}-\mathrm{F}$ (fluorine) bonds and relatively shorter $\mathrm{Cu}-\mathrm{N}$ (nitrogen) bonds (Supplementary Fig. 10 and Supplementary Table 2). Indeed, our analysis of readily available coordination polymers constructed from hexafluorosilicate ions with pyrazine supports our proposal and shows that the bonding of the $\mathrm{Cu}$ (II) with pyrazine leads to a slightly shorter $\mathrm{M}-\mathrm{N}$ bond than the zinc analogue (see Supplementary Table 2$)^{35}$. Accordingly, it is anticipated that successful substitution of $\mathrm{Zn}$ (II) by $\mathrm{Cu}(\mathrm{II})$ will permit access to the desired isostructural SIFSIX-3$\mathrm{Cu}$ with relatively contracted pore size than the parent SIFSIX-3$\mathrm{Zn}$ analogue and subsequent evaluation of its relative $\mathrm{CO}_{2}$ adsorption properties.

Examination of the SIFSIX-3-M adsorption results in the spectra of low-concentration applications (400 p.p.m.-5\%) showed that the $\mathrm{Cu}$ analogue exhibits even steeper adsorption isotherms at very low $\mathrm{CO}_{2}$ concentration (Fig. 3a) translated into the highest uptake ever reported for MOFs without unsaturated metal centres or exposed amino functionality at low $\mathrm{CO}_{2}$ pressures below 38 torr $(0.05 \mathrm{bar})$. This unprecedented finding is even more appealing owing to its fully physical adsorption nature where complete desorption of $\mathrm{CO}_{2}$ was established under vacuum at only $323 \mathrm{~K}$. At 7.6 torr ( $0.01 \mathrm{bar}$ ) SIFSIX-3-Cu uptakes $82.6 \mathrm{~cm}^{3}(\mathrm{STP}) \cdot \mathrm{cm}^{-3}$ versus 55 and $28 \mathrm{~cm}^{3}(\mathrm{STP}) \cdot \mathrm{cm}^{-3}$ for SIFSIX-3-Zn and Mg-MOF-74, respectively. Interestingly, the gravimetric uptake of SIFSIX-3-Cu at 400 p.p.m. and $298 \mathrm{~K}$ $\left(1.24 \mathrm{mmolg}^{-1}\right)$ is ca. 10 and 15 times higher than the corresponding uptakes for SIFSIX-3-Zn $\left(0.13 \mathrm{mmolg}^{-1}\right)$ and Mg-MOF-74 $\left(0.08 \mathrm{mmol} \mathrm{g}^{-1}\right)$ and even higher than the observed uptakes for most amine-supported silica materials (with optimal compromise of amine loading and kinetics $)^{22}$ at $298 \mathrm{~K}$ (for example TRI-PE-MCM-4 $\left.\left(1 \mathrm{mmol} \mathrm{g}^{-1}\right)^{10,22}\right)$. Table 1 summarizes the $\mathrm{CO}_{2}$ adsorption uptake at variable low $\mathrm{CO}_{2}$ concentration (partial pressures) for SIFSIX compounds as compared with Mg-MOF-74 and amine-supported materials (including MOFs), relevant to different trace $\mathrm{CO}_{2}$ removal applications. It is to notice that SIFSIX-3-Cu shows even higher $\mathrm{CO}_{2}$ uptake at 400 p.p.m. and $328 \mathrm{~K}$ as compared with the corresponding uptake at $323 \mathrm{~K}$ for amine functionalized Mg-dobpdc-mmen (Supplementary Table 3).

This increase is mainly attributed to the contracted pore size of the $\mathrm{Cu}$ analogue, which in turn (i) results in a relative increase of the charge density surrounding the adsorbed $\mathrm{CO}_{2}$ molecules and (ii) favors the relatively faster $\mathrm{CO}_{2}$ adsorption kinetics in comparison with $\mathrm{N}_{2}$. Indeed, the four flourine atoms pointing to the channel, in the same plane, are creating a proximal local charge density to the adsorbed $\mathrm{CO}_{2}$ molecule, that is, the $\mathrm{CO}_{2}-\mathrm{F}$ average distance is much narrower in the case of the $\mathrm{Cu}$ analogue

Table $1 \mid \mathrm{CO}_{2}$ adsorption uptake comparison.

\begin{tabular}{|c|c|c|c|c|}
\hline Adsorbent & $\begin{array}{c}\text { Uptake at } 400 \text { p.p.m. } \\
\text { (0.4 mbar) }\end{array}$ & $\begin{array}{c}\text { Uptake at 5,000 p.p.m. } \\
\text { (5 mbar) }\end{array}$ & $\begin{array}{c}\text { Uptake at 10,000 p.p.m. } \\
\text { (10 mbar) }\end{array}$ & $\begin{array}{c}\mathrm{CO}_{2} \text { Qst } \\
\left(\mathrm{kJ} \mathrm{mol}^{-1}\right)\end{array}$ \\
\hline SIFSIX-2-Cu-i & $0.0684^{\star} / 0.2^{\dagger}$ & $0.097^{\star} / 2.7^{\dagger}$ & $0.19^{\star} / 5.32^{\dagger}$ & 32 \\
\hline SIFSIX-3-Zn & $0.13^{\star} / 5.6^{\dagger}$ & $1.12^{\star} / 39.26^{\dagger}$ & $1.53^{\star} / 53.97^{\dagger}$ & 45 \\
\hline SIFSIX-3-Cu & $1.24^{\star} / 43.9^{\dagger}$ & $2.26^{\star} / 79.8^{\dagger}$ & $2.34^{\star} / 82.5^{\dagger}$ & 54 \\
\hline Mg-MOF-74 & $0.088^{\star} / 1.8^{\dagger}$ & $0.7^{\star} / 14.3^{\dagger}$ & $1.27^{\star} / 25.86^{\dagger}$ & 47 \\
\hline Mg-MOF-74-ED ${ }^{\S}, \|$ & $1.5^{\star}$ & ND & ND & ND \\
\hline Mg-dobpdc-mmen ${ }^{\|,}$ & $2^{\star}$ & $2.5^{\star}$ & $2.75^{\star}$ & 70 \\
\hline TRI-PE-MCM-41"I,\# & $1^{\star}$ & $1.45^{\star}$ & $1.6^{\star}$ & 92 \\
\hline HASII\# & $1.7^{\star}$ & ND & ND & ND \\
\hline \multicolumn{5}{|c|}{$\begin{array}{l}\mathrm{ND} \text {, non determined. } \\
\mathrm{CO}_{2} \text { adsorption uptake at various traces of } \mathrm{CO}_{2} \text { concentration and at } 298 \mathrm{~K} \text { in } \\
{ }^{*} \mathrm{mmol} \mathrm{g}^{-1} \text {. } \\
\dagger \mathrm{cm}^{3}(\mathrm{STP}) / \mathrm{cm}^{3} \text {. } \\
\$ \text { Ethylenediamine functionalized } 28 \text {. } \\
\| \text { Chemical adsorbent. } \\
\text { - } N, N \text {-dimethylethylenediamine functionalized }{ }^{27} \text {. } \\
\text { \#Amine-supported silica. } \\
\text { Data in bold represents the data reported for the MOF reported in this work. }\end{array}$} \\
\hline
\end{tabular}


than the relatively open $\mathrm{Zn}$ analogue. It is suggested that the relatively narrower pore size allows and reinforces each $\mathrm{CO}_{2}$ molecule to interact mutually with four fluorine centres, that is, the $\mathrm{CO}_{2}$ molecule can interact potentially with four different surfaces of the square encompassing four fluorine adsorption sites at the same time. The $Q_{s t}$ of $\mathrm{CO}_{2}$ adsorption is an intrinsic property that dictates the affinity of the pore surface toward $\mathrm{CO}_{2}$; this in turn plays a major role in determining the adsorption selectivity and the necessary energy to release $\mathrm{CO}_{2}$ during the regeneration step. Although the $Q_{s t}$ for $\mathrm{CO}_{2}$ was slightly above the typical range of fully reversible $\mathrm{CO}_{2}$ adsorption $\left(30-50 \mathrm{~kJ} \mathrm{~mol}^{-1}\right)^{22}$, SIFSIX-3-Cu was fully and promptly evacuated at $323 \mathrm{~K}$ in vacuum (or under $\mathrm{N}_{2}$ flow environment). As in case of SIFSIX-3-Zn and SIFSIX-2-Cu-i, the $Q_{s t}$ for $\mathrm{CO}_{2}$ adsorption was steady constant up to relatively high $\mathrm{CO}_{2}$ loadings indicating homogenous binding sites over the full range of $\mathrm{CO}_{2}$ loading (Fig. 3b) $)^{23}$. The aforementioned competitive sorption kinetics of $\mathrm{CO}_{2} / \mathrm{N}_{2}: 10 / 90, \mathrm{CO}_{2} / \mathrm{CH}_{4}: 50 / 50, \mathrm{CO}_{2} / \mathrm{H}_{2}: 30 / 70$ gas mixture adsorption experiments (Supplementary Fig. 3) suggest a relatively high selective $\mathrm{CO}_{2}$ adsorption that is plausible due to a synergistic interplay between $\mathrm{CO}_{2}$ sorption thermodynamics and kinetics. This high selectivity was confirmed by performing prediction of $\mathrm{CO}_{2} / \mathrm{N}_{2}$ gas mixture adsorption at equilibrium using Ideal Adsorption Solution Theory (Supplementary Fig. 11). It is important to notice that the derived selectivity at breakthrough time is non-equilibrium data where, similarly to equilibrium Ideal Adsorption Solution Theory results, a complex interplay between strong electrostatic interactions and favourable kinetics toward $\mathrm{CO}_{2}$ drive the high selectivity of $\mathrm{CO}_{2}$ versus $\mathrm{N}_{2}$. The experimental results of the $\mathrm{CO}_{2} / \mathrm{N}_{2}$ gas mixture adsorption testing in dry and humid conditions revealed that the $\mathrm{CO}_{2}$ apparent selectivity at 1,000 p.p.m. $\mathrm{CO}_{2}$ on SIFSIX-3-Cu was not affected by the presence of humidity as shown from the column breakthrough tests performed on both compounds at the relative humidity (RH) of $74 \%$ (Fig. 4a). This unprecedented finding was also valid in case of SIFSIX-3-Zn for the removal of low and higher $\mathrm{CO}_{2}$ concentration $^{23}$.

Finally, as was demonstrated for SIFSIX-3-Zn, SIFSIX-3-Cu is a recyclable and moisture stable MOFs as inferred from the PXRD performed on associated samples after at least four cycles of $\mathrm{CO}_{2}$ adsorption and breakthrough runs under dry and humid conditions (74\% RH) (Supplementary Fig. 12).

In conclusion, we showed herein how a material design and engineering approach to pore size control in combination with suitable energetics of favourable electrostatics from an array of inorganic anions affords novel SIFSIX-3-Cu MOF with exceptional $\mathrm{CO}_{2}$ uptake and selectivity in the context of air capture and trace $\mathrm{CO}_{2}$ removal. This unique material exhibits very high $\mathrm{CO}_{2}$ sorption energetics but fully reversible physical driven adsorptiondesorption operations at very mild conditions, without the welldocumented drawbacks associated with amine reactive chemistry.

This work shows for the first time that MOFs, thanks to their ability for rational pore size modification and inorganic-organics moieties substitution, offer remarkable $\mathrm{CO}_{2}$ physical adsorption attributes in highly diluted gas streams that other class of plain materials are unable to attain. Further work is underway to use the learning gained in the case of SIFSIX-3-M compounds to develop topologically and chemically different MOFs, aiming to target novel MOFs with suitable pore size and high charge density, for use in trace $\mathrm{CO}_{2}$, low and high concentration $\mathrm{CO}_{2}$ removal.

\section{Methods}

Preparation of SIFSIX-3-Cu. A methanol solution $(5.0 \mathrm{ml})$ of pyrazine (pyz, $0.30 \mathrm{~g}, 3.0 \mathrm{mmol})$ was layered in a glass tube onto a methanol solution $(5.0 \mathrm{ml})$ of $\mathrm{CuSiF}_{6} \times \mathrm{H}_{2} \mathrm{O}(0.325 \mathrm{~g}, 0.6 \mathrm{mmol})$. On layering, a fast formation of light violet powder was observed, and the powder was left for $24 \mathrm{~h}$ in the mother solution.
The powder was then collected and washed extensively with methanol and then dried under vacuum.

Characterization. The PXRD patterns were recorded using a Panalytical X'pert PRO MPD X-ray Diffractometer with $\mathrm{Cu} K \alpha$ radiation $(\lambda=0.15418 \mathrm{~nm}, 45 \mathrm{kV}$, $40 \mathrm{~mA})$.

Low-pressure adsorption. The low-pressure gas sorption isotherms were collected on Autosorb-1C (Quantachrome Instruments) Surface Area and Porosity Analyzer after activation of SIFSIX-3-Cu as follows. As-synthesized SIFSIX-3-Cu was exchanged with methanol for 3 days. The sample was degassed at room temperature under high vacuum $(<5 \mu \mathrm{m} \mathrm{Hg})$ for $12 \mathrm{~h}$, then to $323 \mathrm{~K}$ for another $12 \mathrm{~h}$ before adsorption analysis. The apparent surface areas of SIFSIX-3-Cu were determined from the $\mathrm{CO}_{2}$ adsorption isotherm collected at $298 \mathrm{~K}$, respectively by applying the BET and Langmuir models. The determination of the isosteric heat of adsorption $\left(Q_{s t}\right)$ for $\mathrm{CO}_{2}$ was estimated by applying the Clausius-Clapeyron expression using the $\mathrm{CO}_{2}$ adsorption isotherms measured at 298, 308, 318 and $328 \mathrm{~K}$. The bath temperature was precisely controlled using a Julabo recirculating control system containing a mixture of ethylene glycol and water. Data points below 0.76 Torr were not used for this calculation, in order to avoid possible artifacts at very low coverage.

Measurement of equilibrium and kinetics of adsorption. Adsorption equilibrium measurements of pure gases were performed using a Rubotherm gravimetric-densimetric apparatus (Bochum, Germany) (Supplementary Fig. 13), composed mainly of a magnetic suspension balance and a network of valves, mass flowmeters and temperature and pressure sensors. The magnetic suspension balance overcomes the disadvantages of other commercially available gravimetric instruments by separating the sensitive microbalance from the sample and the measuring atmosphere and is able to perform adsorption measurements across a wide pressure range, that is, from 0 to $20 \mathrm{MPa}$. The adsorption temperature may also be controlled within the range of 77 to $423 \mathrm{~K}$. In a typical adsorption experiment, the adsorbent is precisely weighed and placed in a basket suspended by a permanent magnet through an electromagnet. The cell in which the basket is housed is then closed and vacuum or high pressure is applied. The gravimetric method allows the direct measurement of the reduced gas adsorbed amount $\Omega$. Correction for the buoyancy effect is required to determine the excess and absolute adsorbed amount using equations 1 and 2, where $V_{\text {adsorbent }}$ and $V_{\text {ss }}$ and $V_{\text {adsorbed }}$ phase refer to the volume of the adsorbent, the volume of the suspension system and the volume of the adsorbed phase, respectively.

$$
\begin{gathered}
\Omega=m_{\text {absolute }}-\rho_{\text {gas }}\left(V_{\text {adsorbent }}+V_{\mathrm{ss}}+V_{\text {adsorbed-phase }}\right) \\
\Omega=m_{\text {excess }}-\rho_{\text {gas }}\left(V_{\text {adsorbent }}+V_{\mathrm{SS}}\right)
\end{gathered}
$$

The buoyancy effect resulted from the adsorbed phase maybe taken into account via correlation with the pore volume or with the theoretical density of the sample.

Kinetic studies of $\mathrm{CO}_{2}$ and $\mathrm{CO}_{2} / \mathrm{N}_{2}: 10 / 90$ adsorption on SIFSIX-3-Cu was carried out using the Rubotherm gravimetric apparatus operating in dynamic regime. Initially, SIFSIX-3-Cu was properly evacuated at $323 \mathrm{~K}$ in vacuum. In order to achieve an immediate constancy of pressure $(0.5$ bar $)$ during kinetics tests and avoid the often noisy uptake during the rapid introduction of the studied gas, an initial baseline was set-up using helium gas at 0.5 bar for single gases and 1 bar for mixture, then the studied single gas or mixture is flushed with a flow of $300 \mathrm{ml} \mathrm{min}^{-1}$ to avoid any dependence of the kinetics on the mass flow controller.

Column breakthrough tests. The experimental set-up used for dynamic breakthrough measurements is shown in Supplementary Fig. 13. The gas manifold consisted of three lines fitted with mass flow controllers Line 'A' is used to feed an inert gas, most commonly helium, to activate the sample before each experiment. The other two lines, 'B' and ' $C$ ' feed a mixture of $\mathrm{CO}_{2}$ and other gases like $\mathrm{N}_{2}, \mathrm{CH}_{4}$ and $\mathrm{H}_{2}$. Hence, gas mixtures with concentrations representative of different industrial gases may be prepared. Whenever required, gases flowing through lines ' $\mathrm{B}$ ' and ' $\mathrm{C}$ ' may be mixed before entering a column packed with SIFSIX-3-Cu using a four-way valve. The stainless steel column was $27 \mathrm{~mm}$ in length with $4 \mathrm{~mm}$ of inner $(6.4 \mathrm{~mm}$ outer) diameter. The column downstream was monitored using a Hiden analytical mass spectrometer. In a typical experiment, $0.1-0.4 \mathrm{~g}$ of adsorbent was treated at $298 \mathrm{~K}$ overnight under helium flow of $5 \mathrm{ml} \mathrm{min}^{-1}$ at $323 \mathrm{~K}$, then the gas flow was switched to the desired gas mixture at the same flow rate. The complete breakthrough of $\mathrm{CO}_{2}$ and other species was indicated by the downstream gas composition reaching that of the feed gas. Experiments in the presence of $74 \% \mathrm{RH}$ were performed by flowing the gas mixture through water vapour saturator at $20^{\circ} \mathrm{C}$.

The selectivity of $\mathrm{CO}_{2}$ over $\mathrm{N}_{2}$ is calculated using the equation below:

$S_{\frac{\mathrm{CO}_{2}}{\mathrm{~N}_{2}}}=\frac{\left(\text { Uptake } \mathrm{CO}_{2} / \text { Uptake } \mathrm{CO}_{2} \text { and } \mathrm{N}_{2}\right) /\left(\text { Uptake } \mathrm{N}_{2} / \text { Uptake } \mathrm{CO}_{2} \text { and } \mathrm{N}_{2}\right)}{\text { Composition } \mathrm{CO}_{2} / \text { Composition } \mathrm{N}_{2}}$ 


\section{References}

1. Lackner, K. S. \& Wright, A. B. Removal of carbon dioxide from air. WO 2010022399 A1 (2010).

2. Major, C. J., Sollami, B. J. \& Kammerme, K. Carbon dioxide removal from air by adsorbents.. Ind. Eng. Chem. Process Des. Dev. 4, 327-333 (1965).

3. Stolaroff, J. K., Keith, D. W. \& Lowry, G. V. Carbon dioxide capture from atmospheric air using sodium hydroxide spray. Environ. Sci. Technol. 42, 2728-2735 (2008).

4. Nikulshina, V., Gebald, C. \& Steinfeld, A. $\mathrm{CO}_{2}$ capture from atmospheric air via consecutive $\mathrm{CaO}$-carbonation and $\mathrm{CaCO}_{3}$-calcination cycles in a fluidized-bed solar reactor. Chem. Eng. J. 146, 244-248 (2009).

5. Goeppert, A., Czaun, M., Prakash, G. K. S. \& Olah, G. A. Air as the renewable carbon source of the future: An overview of $\mathrm{CO}_{2}$ capture from the atmosphere. Energ. Environ. Sci. 5, 7833-7853 (2012).

6. Rege, S. U., Yang, R. T. \& Buzanowski, M. A. Sorbents for air prepurification in air separation. Chem. Eng. Sci. 55, 4827-4838 (2000).

7. Rege, S. U., Yang, R. T., Qian, K. Y. \& Buzanowski, M. A. Air-prepurification by pressure swing adsorption using single/layered beds. Chem. Eng. Sci. 56, 2745-2759 (2001)

8. Santos, J. C., Magalhaes, F. D. \& Mendes, A. Contamination of zeolites used in oxygen production by PSA: effects of water and carbon dioxide. Ind. Eng. Chem. Res. 47, 6197-6203 (2008).

9. Haring, H. W. Industrial Gases Processing (Wiley-VCH Verlag GmbH \& Co, 2008).

10. Belmabkhout, Y., Serna-Guerrero, R. \& Sayari, A. Amine-bearing mesoporous silica for $\mathrm{CO}_{2}$ removal from dry and humid air. Chem. Eng. Sci. 65, 3695-3698 (2010).

11. Kordesch, K. et al. Alkaline fuel cells applications. J. Power Sources 86, 162-165 (2000).

12. Ernsting, J. Breathing systems in aerospace. IEE Seminar. Low Flow Anaesthesia Breathing Systems-Technology, Safety and Economics (Ref. No.1999/060), 7/1-4 (1999).

13. Satyapal, S., Filburn, T., Trela, J. \& Strange, J. Performance and properties of a solid amine sorbent for carbon dioxide removal in space life support applications. Energ. Fuel 15, 250-255 (2001).

14. Mattox, E. M., Knox, J. C. \& Bardot, D. M. Carbon dioxide removal system for closed loop atmosphere revitalization, candidate sorbents screening and test results. Acta Astronaut. 86, 3946 (2013).

15. Moore, P. Miner protection. Min. Mag. 196, 35-41 (2007).

16. Dosch, M. P. The anesthesia gas machine http://www.udmercy.edu/crna/agm (2006).

17. Dosch, M. P. The anesthesia gas machine http://www.udmercy.edu/crna/agm/ 07.htm (2012)

18. Wilmer, C. E., Farha, O. K., Bae, Y.-S., Hupp, J. T. \& Snurr, R. Q. Structure-property relationships of porous materials for carbon dioxide separation and capture. Energ. Environ. Sci. 5, 9849-9856 (2012).

19. Sayari, A. \& Belmabkhout, Y. Stabilization of amine-containing $\mathrm{CO}_{2}$ adsorbents: dramatic effect of water vapor. J. Am. Chem. Soc. 132, 6312-6313 (2010).

20. Caskey, S. R., Wong-Foy, A. G. \& Matzger, A. J. Dramatic tuning of carbon dioxide uptake via metal substitution in a coordination polymer with cylindrical pores. J. Am. Chem. Soc. 130, 10870-10871 (2008).

21. Sumida, K. et al. Carbon dioxide capture in metal-organic frameworks. Chem. Rev. 112, 724-781 (2012).

22. Sayari, A., Belmabkhout, Y. \& Serna-Guerrero, R. Flue gas treatment via $\mathrm{CO}_{2}$ adsorption. Chem. Eng. J. 171, 760-774 (2011).

23. Nugent, P. et al. Porous materials with optimal adsorption thermodynamics and kinetics for $\mathrm{CO}_{2}$ separation. Nature 495, 80-84 (2013).

24. Xue, D. X. et al. Tunable rare-earth fcu-MOFs: A platform for systematic enhancement of $\mathrm{CO}_{2}$ adsorption energetics and uptake. J. Am. Chem. Soc. 135, 7660-7667 (2013).

25. Choi, S., Drese, J. H., Eisenberger, P. M. \& Jones, C. W. Application of aminetethered solid sorbents for direct $\mathrm{CO}_{2}$ capture from the ambient air. Environ. Sci. Technol. 45, 2420-2427 (2011).
26. Goeppert, A., Czaun, M., Surya Prakash, G. K. \& Olah, G. A. Air as the renewable carbon source of the future: an overview of $\mathrm{CO}_{2}$ capture from the atmosphere. Energy Environ. Sci. 5, $7833-7853$ (2012).

27. McDonald, T. M. et al. Capture of carbon dioxide from air and flue gas in the alkylamine-appended metal-organic framework mmen- $\mathrm{Mg}_{2}$ (dobpdc). J. Am. Chem. Soc. 134, 7056-7065 (2012).

28. Choi, S., Watanabe, T., Bae, T.-H., Sholl, D. S. \& Jones, C. W. Modification of the Mg-DOBDC MOF with amines to enhance $\mathrm{CO}_{2}$ adsorption from ultradilute Gases. J. Phys. Chem. Lett. 3, 1136-1141 (2012).

29. Guillerm, V. et al. Porous organic polymers with anchored aldehydes: A new platform forpost-synthetic amine functionalization en route for enhanced $\mathrm{CO}_{2}$ adsorption properties. Chem. Commun. 50, 1937-1940 (2013).

30. Le Bail, A. Monte Carlo indexing with McMaille. Powder Diffr. 19, 249-254 (2004).

31. Le Bail, A., Duroy, H. \& Fourquet, J. L. Ab-initio structure determination of $\mathrm{LiSbWO}_{6}$ by X-ray powder diffraction. Mater. Res. Bull. 23, 447-452 (1988).

32. Rodriguez-Carvajal, J. Abstracts of the Satellite. Meeting on Powder Diffraction of the XV Congress of the IUCr, 127 (1990).

33. Conley, B. D., Yearwood, B. C., Parkin, S. \& Atwood, D. A. Ammonium hexafluorosilicate salts. J. Fluorine Chem. 115, 155-160 (2002).

34. Xiang, S. et al. Microporous metal-organic framework with potential for carbon dioxide capture at ambient conditions. Nat. Commun. 3, 956-965 (2012).

35. Uemura, K., Maeda, A., Maji, T. K., Kanoo, P. \& Kita, H. Crystal structures and adsorption properties of ultramicroporous coordination polymers constructed ions from hexafluorosilicate ions and pyrazine. Eur. J. Inorg. Chem. 2329-2337 (2009).

\section{Acknowledgements}

Research reported in this publication was supported by the King Abdullah University of Science and Technology (KAUST).

\section{Author contributions}

O.S., Y.B. and M.E. contributed to the conceptual approach in designing the synthetic experiments; O.S. and Z.C. carried out the synthetic experiments; V.G. and K.A. conducted and interpreted the crystallographic experiments; Y.B. and A.C. conducted and interpreted low-pressure sorption experiments; Y.B. conducted and interpreted column breakthrough experiments; O.S., Y.B. and M.E. wrote the manuscript.

\section{Additional information}

Accession codes: The X-ray crystallographic data for structure reported in this article has been deposited at the Cambridge Crystallographic Data Centre (CCDC), under deposition number CCDC 970790. The data can be obtained free of charge from The Cambridge Crystallographic Data Center via www.ccdc.cam.ac.uk/data_request/cif.

Supplementary Information accompanies this paper at http://www.nature.com/ naturecommunications

Competing financial interests: The authors declare no competing financial interests

Reprints and permission information is available online at http://npg.nature.com/ reprintsandpermissions/

How to cite this article: Shekhah, O. et al. Made-to-order metal-organic frameworks for trace carbon dioxide removal and air capture. Nat. Commun. 5:4228 doi: $10.1038 /$ ncomms5228 (2014)

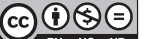

This work is licensed under a Creative Commons AttributionNonCommercial-NoDerivs 4.0 International License. The images or other third party material in this article are included in the article's Creative Commons license, unless indicated otherwise in the credit line; if the material is not included under the Creative Commons license, users will need to obtain permission from the license holder to reproduce the material. To view a copy of this license, visit http:// creativecommons.org/licenses/by-nc-nd/4.0/ 